\title{
Ginger as a commercial product in China
}

\begin{abstract}
Most peoples have used Ginger as traditional medicine or spices for food during thousands of years ago. Ginger is an important component of traditional medicine used widely as an alternative or free medicines in most parts of the world. Previous studies review the influence and important of Ginger as a commercial product in China, so we found that Ginger has a magical therapeutics to inhibit the diseases, moreover it will become source of incomes if it is marketed in a good way.
\end{abstract}

Keywords: ginger; traditional medicine; China
Volume 5 Issue I - 2020

\author{
Rasheed Abdulwase,' Abdul Baset Abbas, ${ }^{2}$ \\ Shuangsheng Yan ${ }^{1,3}$ \\ 'Department of Business Management, China Pharmaceutical \\ University, China \\ ${ }^{2}$ Department of Life Science, China Pharmaceutical University, \\ China \\ ${ }^{3}$ Department of Social Science, China Pharmaceutical University, \\ China
}

Correspondence: Shuangsheng Yan, Associate Professor, Director, the Philosophy of Teaching and Research Office, Department of Social Science, International Pharmaceutical Business School, China Pharmaceutical University, No 639, Longmian Avenue, Jiangning District, Nanjing, P.R. China, 211198 , Tel+8613305I517 82, Email ys@cpu.edu.cn, reshiidma@ gmail.com, abduabbas204@hotmail.com,yss@cpu.edu.cn

Received: November 13, 2019 | Published: January 03, 2020

\section{Introduction}

Ginger (Zingiber officinal) is usually found in the grassland of the wetlands as a grass which can reach about 2 meters in height. The plant can be named differently in different parts of the world, for example, jiāng or Sang Kyung in Chinese, Uday or Adrak in Hindi, Gabi or Alia in Indonesia, Gimber in Dutch, Gingembre in French, Inghwar in German, Zengeru in Italian, Jengibre in Spanish. Ginger belongs to the Zingiberaceae family and contains 85 kinds of aromatic herbs. ${ }^{1-3}$ In addition the Ginger is an origin in Southeast Asia so the best climate for growing ginger is Southeast Asia, although is grown in most tropical countries such as Jamaica, China, India, Nigeria and Haiti. Whosesoever global production of ginger in 2013 reached 2100 million $\mathrm{kg}$. India accounted for $33 \%$ of total production in the world, followed by China with 19\%, Nepal with third and Indonesia and Nigeria respectively. As a result that the countries of Middle East most consumed for it. ${ }^{4}$

Active ingredients of ginger, In general more than 60 active ingredients are known to exist in ginger, which have been broadly divided into volatile and nonvolatile compounds. Also contains a nutritional value with 80 calories, proteins1.82, carbohydrate $18 \mathrm{~g}$, fats0.75 g, food fiber2 $\mathrm{g}$, vitamin C5 g, vitamin B30.75 g, vitamin B60.16 g, potassium $415 \mathrm{~g}$ and Iron0.6 g. Plant root is rich with insulin, antolokton, antispasmodic and essential oils. The nucleus of the nuclei contains $3-6 \%$ fatty oil, $9 \%$ protein, $60-70 \%$ carbohydrate, $3-8 \%$ raw fiber, about $8 \%$ ash, $9-12 \%$ water, $2-3 \%$ of volatile oil. Nitrogen compounds are usually claimed to have medicinal value. ${ }^{2,5-7}$

Therapeutically Ginger has been used as Ayurvedic medicine from the Vedic period and is called "mahaaushadhi" which means great medicine. In traditional medicine, it was used as an air freshener. The Greek physician Galenus used ginger as a supplement to the body. ${ }^{8}$
Recently studies have shown that it contains antioxidants, anti-cancer, anti-inflammatory, antipoptotic, anti-hyperglycemic, antihyperlipidemic and anti-vomiting procedures. Due to its various active ingredients, ginger is considered a safe medicinal plant with few adverse effects and is not important. Ginger contains substances that regulate the functioning of the digestive system, especially preventing nausea and vomiting. It is usually recommended to consume 4-2 g daily, divided into 2-3 servings, to relieve pregnancy nausea. ${ }^{9}$

Ginger contains anti-inflammatory substances, which can contribute to the relief of arthritis. Contains anti-oxidant and anticancer substances. It is recommended to use ginger as a healthy spice in particular, in frequent intervals in the weekly menu, and as a natural treatment to relieve nausea and inflammation. Ginger is generally considered to have many benefits for various health conditions. According to some scientific sites, what they have been found about the benefits of ginger medically proven in laboratory studies on animals was: relieve swelling, reduce blood sugar, cholesterol Reduction, protection against Alzheimer's disease, prevention of blood clotting. ${ }^{10,11}$

However, according to experiments, studies and applications of traditional medicine and physiotherapy, it is possible to get more benefits for ginger, whether by eating boiled or oil or powder use or in other ways. By the way has toxic effects if we use high dose of ginger 5 times $(2500 \mathrm{mg} / \mathrm{kg})$ can be toxic by causing severe hypotension and slow heartbeat with the induction of glass changes and the faintness of certain nuclei in the pre-necrosis muscle fibers. But more research is needed to know for sure how it affects humans. ${ }^{12}$

Commercially Ginger-containing commercial represents commercial products in three different forms (ground ginger powder, Ginger tea leaf, and ginger crystal) Ginger is included in the list of medicinal herbs and is usually used as a spice, and can be taken fresh 
or drink, squeezed or boiling or use powder or oil for therapeutic purposes. ${ }^{13,14}$

\section{Conclusion}

Ginger is one of the famous herb and spice is used by most of the people in the world. So the most important thing of this product which will be source of incomes, if China will invest it according to the production process and know the amount of income to be earned by China. If they are focusing on other countries that have not good area to grow up it, through use marketing mix, promotion to show the important information, health benefits of Ginger and make guidelines for how to use it in consideration distribution channels are close to the consumers.

\section{Acknowledgments}

We acknowledge the teachers Eric and Abdulalem Mohammed for their ideas.

\section{Conflicts of interest}

The authors declare that there is no conflict of interest.

\section{Reference}

1. Brown D. Herbal: the essential guide to herbs for living: Pavilion Books; 2015.

2. AL KHDRI AMA. Effect of ginger (Zingiber officinale) and thyme (Thymus vulgaris) dietary supplementation on productive and immunological performance of broiler: University of Mosul; 2009.

3. Vasala P. Ginger. Handbook of herbs and spices: Elsevier; 2012. p. 319-335.
4. Daily JW, Yang M, Kim DS, et al. Efficacy of ginger for treating Type 2 diabetes: A systematic review and meta-analysis of randomized clinical trials. Journal of Ethnic Foods. 2015;2(1):36-43.

5. Imtiyaz S, Raheman K, Sultana A, et al. Zingiber officinale Rosc.: A traditional herb with medicinal properties. TANG. 2013;3.

6. Shao X, Lv L, Parks T, et al. Quantitative analysis of ginger components in commercial products using liquid chromatography with electrochemical array detection. J Agric Food Chem. 2010;58(24):12608-12614.

7. Abeysekera W, Illeperuma C, Amunugoda P, Wijeratnam S. Comparison of ginger varieties dried at different temperatures for oil and oleoresin contents. Department of Food Science \& Technology, Faculty of Agriculture, University of Peradeniya, Sri Lanka. 2005;42:34-42.

8. Palatty PL, Haniadka R, Valder B, et al. Ginger in the prevention of nausea and vomiting: a review. Crit Rev Food Sci Nutr. 2013;53(7):659-669.

9. Hartini TNS, Padmawati RS, Lindholm L, et al. The importance of eating rice: changing food habits among pregnant Indonesian women during the economic crisis. Soc Sci Med. 2005;61(1):199-210.

10. Foreman J. TURMERIC/CURCUMIN BENEFITS

11. McWherter JF, Reiss U. Topical anti-inflammatory compositions and uses thereof. Google Patents; 2014.

12. Elkhishin IA, Awwad IA. A study of the cardiovascular toxic effects of Zingiber officinale (ginger) in adult male albino rats and its possible mechanisms of action. Mansoura J Forensic Med Clin Toxicol. 2009; 17(2):109-127.

13. Kubra IR, Rao LJM. An impression on current developments in the technology, chemistry, and biological activities of ginger (Zingiber officinale Roscoe). Crit Rev Food Sci Nutr. 2012;52(8):651-688.

14. Bliss ES. Capsaicin in attenuating metabolic syndrome: University of Southern Queensland; 2017. 